\title{
A IMPORTÂNCIA DA BIÓPSIA MUSCULAR NO DIAGNÓSTICO DE NEUROMIOPATIAS
}

\author{
LUIZ FERNANDO BLEGGI-TORRES $P^{*}$, LÚCIA DE NORONHA * *
}

\begin{abstract}
RESUMO - As doenças neuromusculares têm quadro clínico variado e manifestam-se principalmente em pacientes jovens, determinando incapacidade funcional progressiva. Avaliação clínica, eletromiografia, bioquímica sanguínea e biópsia muscular são indispensáveis para o correto diagnóstico etiológico. Apresentamos casuística de 124 casos diagnosticados por biópsia muscular com histoquímica enzimática, microscopia eletrônica e avaliação morfométrica da variação no diâmetro das fibras afetadas, comentando os principais elementos diagnósticos anátomo-patológicos. Necrose muscular, grande variabilidade no diâmetro de fibras e infiltração adiposa muscular predominam nos quadros miopáticos distróficos, que representaram $26 \%$ de nossos casos. Redução volumétrica com angulação das fibras sugeriu origem neurogênica, sendo a alteração importante detectada em $27 \%$ de nossos diagnósticos. Miopatia mitocondrial caracteriza-se por acúmulos periféricos de grande quantidade de mitocôndrias com ultraestrutura alterada. Cuidados especiais na escolha e coleta da amostra muscular podem minimizar achados inespecíficos ou alterações tipo estadio terminal que impossibilitam a caracterização adequada da doença.
\end{abstract}

PALAVRAS-CHAVE: miopatia, doenças neuromusculares, neuro-miopatias, histoquimica, microscopia eletrônica.

\section{The role of muscle biopsy in the diagnosis of neuromuscular diseases}

SUMMARY - Most of the neuromuscular diseases have similar clinical presentation affecting mainly young patients. Clinical observations, serum enzymes, eletromyographic studies and muscle biopsy are required for correct diagnosis. The authors show the results of morphological observations of a series of 124 muscle biopsies studied between 1988 and 1992 using conventional paraffin embedded material, frozen sections of muscle tissue stained by several histochemical techniques, electron microscopic observations and, in some cases, morphometric analysis of the smaller diameter of at least 100 random muscle fibres. Neurogenic atrophy was present in $27 \%$ of the cases $(n=33)$, dystrophic muscle was diagnosed in $26 \%$, mitochondrial myopathy in $7 \%$ while inflammatory and metabolic myopathies were less frequent. In the group of muscle dystrophy most cases were of Duchenne type showing great variation in fibre size ranging from 10 to 110 microns (mean=30 to 70 microns). There was also muscle necrosis and fatty changes. Neurogenic biopsies showed fibre atrophy with clustering of nuclei and group atrophy. Electron microscopic observations in cases of Werdnig-Hoffmann showed tiny fibres with less than 5 microns in great dimension and also with redundant basal laminae. Cases of mitochondrial myopathy showed the classical ragged red fibres and many different mitochondrial abnormalities under the electron microscope. Many cases $(33 \%)$ showed only minor structural abnormalities or end-stage alterations with marked fatty infiltration and fibrosis so that a definitive diagnosis failed to be achieved. The correct selection and handling of muscle biopsies is important for adequate diagnosis in neuromuscular pathology.

KEY WORDS: myopathy, neuromuscular diseases, muscle histochemistry, electron microscopy.

Unidade de Patologia Neuro-Muscular do Hospital Nossa Senhora das Graças e Setor de Neuropatologia e Microscopia Eletrônica do Serviço de Anatomia Patológica do Hospital de Clínicas da Universidade Federal do Paraná (UFPR), Curitiba: *PhD Neuropatologista e Professor Adjunto do Departamento de Patologia Médica da UFPR; **Estagiária e Doutoranda de Medicina. Aceite: 12-fevereiro-1994.

Dr. Luiz Fernando Bleggi Torres - Unidade de Patologia Neuro-Muscular, Centro de Patologia de Curitiba Ltda., Hospital Nossa Senhora das Graças - Rua Alcides Munhoz 433 - 80510-040 Curitiba PR - Brasil. FAX: (041) 264.5872. 
As doenças neuromusculares afetam principalmente jovens com quadros clínicos por vezes dramáticos e incapacidade funcional. Sua caracterização correta é importante, pois determina a evolução clínica e o prognóstico permitindo, também, aconselhamento genético nos casos de caráter familial. O diagnóstico das doenças neuromusculares requer avaliação clínica, eletromiografia, bioquímica sanguínea e biópsia muscular.

Neste estudo, é relatada a análise de 124 biópsias consecutivas realizadas no período de 1988 a 1992 na Unidade de Patologia Neuro-Muscular (UPNM) do Hospital Nossa Senhora das Graças com apoio do Setor de Neuropatologia e Microscopia Eletrônica do Hospital de Clínicas, discutindose os achados histológicos, histoquímicos e ultraestruturais importantes para o diagnóstico.

\section{MATERIAL E MÉTODOS}

O material consta de 124 biópsias musculares enviadas à UPNM a fresco, onde metade do fragmento tecidual recebido foi congelado em nitrogênio líquido a -160 graus e cortado em criostato a 4 micrômetros para posterior estudo enzimático. A outra metade foi fixada em formalina tamponada a $10 \%$ para estudo convencional em parafina, corada com hematoxilina-eosina e hematoxilina van Gieson.

O estudo enzimático incluiu várias técnicas especiais de coloração como tricrômico de Gomori, SDH, NADH, miosina ATPase, fosfatase ácida, Oil red $\mathrm{O}$, Sudan Black e PAS ${ }^{2}$. A avaliação da variação do diâmetro das fibras foi realizada em casos selecionados através da medição de seu menor diâmetro em pelo menos 100 fibras aleatórias, em diferentes campos de grande aumento com o auxílio de gratícula ocular aferida por micrômetro de platina. Os resultados foram expressos em histogramas e aferidos juntamente com controles, sempre que possível pareados para sexo e idade ${ }^{7}$. Em alguns casos a biópsia foi submetida a estudo por microscopia eletrônica. Nestes, parte do espécime foi previamente fixada em glutaraldeído a 3\%, pós-fixada em ósmio, tratada com álcool e éxido de propileno e incluída em araldite, para cortes semi-finos corados com azul de toluidina e ultrafinos corados com citrato de chumbo e acetato de uranila. Observação em microscópio Philips EM300 ${ }^{17}$.

\section{RESULTADOS E COMENTÁRIOS}

Das 124 biópsias que fazem parte deste estudo, $77(62,10 \%)$ eram de pacientes do sexo masculino e $47(37,90 \%)$ de pacientes do sexo feminino. A faixa etária oscilou de alguns meses de vida a 79 anos (média: 23 anos). As miopatias prevaleceram na primeira e na terceira décadas, em que encontramos a distrofia tipo Duchenne com início em torno dos 3 a 5 anos, enquanto a tipo Becker pode aparecer até a terceira década. Já ao observarmos o grupo das atrofias neurogênicas notamos dois grandes picos, um na primeira década e que corresponde à doença de Werdnig-Hoffmann, e o outro na quinta e sexta décadas atribuído às doenças do neurônio motor inferior de aparecimento mais tardio. Nas doenças neurogênicas, aproximadamente $27 \%$ do total $(n=33)$, as fibras musculares sofrem atrofia com redução volumétrica e assumem aspecto angulado ou arredondado, notando-se agrupamentos nucleares devidos a diminuição do volume do sarcoplasma com consequente aproximação dos núcleos. Inicialmente as fibras lesadas têm distribuição aleatória, mas com o evoluir do processo aparecem pequenos grupos de fibras atrofiadas (Fig 1). Com a evolução, pode ocorrer reinervação colateral formando-se grupos de fibras de um mesmo subtipo histoquímico e o tecido muscular perde seu aspecto normal, em mosaico, visto numa preparação com miosina ATPase. Na doença de Werdnig-Hoffmann observamos intensa atrofia muscular, com fibras redondas menores que 5 micrômetros e detectáveis principalmente em microscopia eletrônica (Fig 2). As distrofias musculares corresponderam a $26 \%(n=32)$ em nossa série enquanto Lee ${ }^{12}$ detectou, em estudo de 200 biópsias musculares de pacientes de Singapura, incidência de $12 \%$ de casos de distrofia muscular. Werneck ${ }^{19}$ relata incidência aproximada de $39 \%$. Tal diferença deve representar vício de amostragem sendo necessários estudos clínicos e epidemiológicos para melhor avaliação.

As distrofias são doenças primárias das fibras musculares que afetam diversas espécies animais ${ }^{18}$, inclusive o ser humano, apresentando-se com necrose, fagocitose, regeneração muscular e variação no tamanho das fibras (Fig 3). Avaliação morfométrica demonstrou que diâmetros das fibras oscilaram de 10 a 110 micrômetros (normal: 30 a 70 micrômetros). Há, ainda, infiltração 


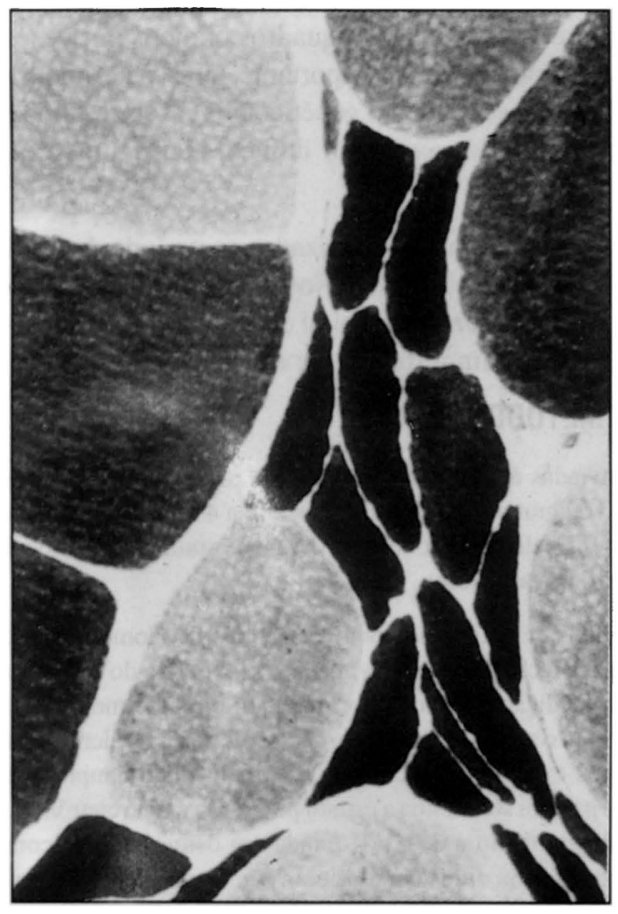

Fig I. Atrofia neurogênica demonstrando atrofia em grupo de fibras tipo 1 as quais têm aspecto angulado com acentuada redução volumétrica se comparadas às demais fibras preservadas. Miosina ATPase pH $9.4 \times 400$.

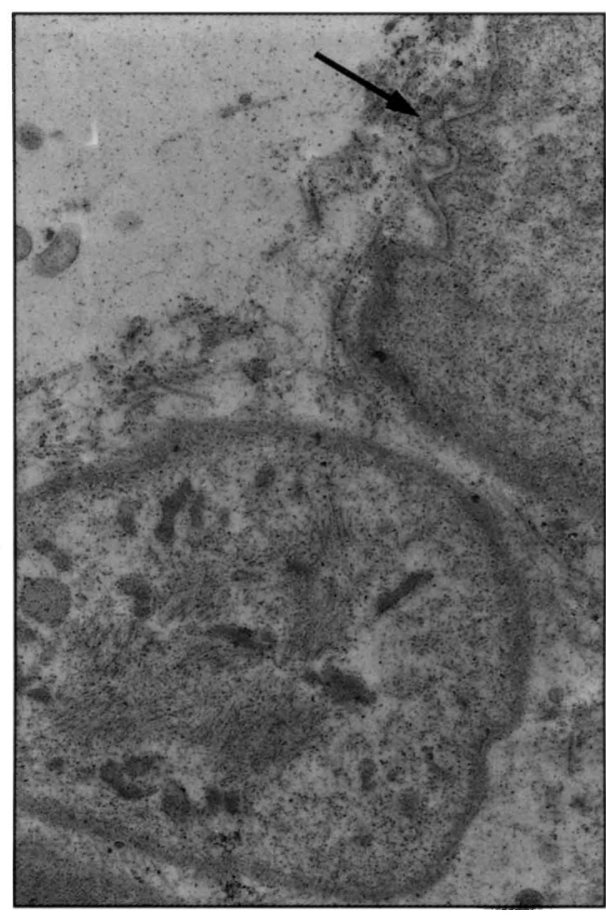

Fig 2. Microscopia eletrônica de músculo de paciente com Werdnig-Hoffmann demonstrando fibras pequenas com perda de estrutura interna $e$ pregueamento de membrana celular com redundância de lâmina basal (seta). x15000.

gordurosa que leva a pseudo-hipertrofia de grupos musculares. São classificadas de acordo com o quadro clínico, severidade e padrão de transmissão genética. Nossa casuística revelou que distrofia tipo Duchenne corresponde a $31,25 \%$ dos casos diagnosticados $(n=10)$, tipo congênita e cinturas a $25 \%$ dos casos cada ( $\mathrm{n}=8$ ), tipo face-escápulo-umeral a $12,5 \%$ dos casos $(\mathrm{n}=4)$ e distrofia de Becker e miotônica a aproximadamente $3 \%$ dos casos cada $(n=1)$. Acredita-se ocorrer, nestas entidades, anormalidade intrínseca da fibra muscular que leva a sua destruição. Especula-se que na distrofia tipo Duchenne ocorra desordem a nível de membrana celular, com afluxo de íons cálcio em excesso provocando a morte celular. Este defeito poderia estar ligado a deficiência de distrofina que é uma proteína do citoesqueleto encontrada na superfície interna da membrana de fibras musculares normais, porém ausente em pacientes com Duchenne e deficitária nos pacientes com distrofia de Becker ${ }^{6,8,11}$. Recentes observações na estrutura primária das glicoproteínas corroboram a hipótese de que a redução nesta substância em pacientes com Duchenne e Becker levaria a perda de ligações entre o sarcolema e a matriz extracelular, tornando as fibras mais susceptíveis a necrose?

A elevada incidência nesta casuística de miopatias mitocondriais, doença rara, deve-se à identificação de diversos membros de uma mesma família residente nesta localidade e afetados por miopatia mitocondrial e epilepsia mioclônica ${ }^{1}$. As miopatias mitocondriais (aproximadamente $7 \%$ dos nossos casos) compõem grupo complexo e heterogêneo de desordens neuromusculares devidas a defeitos bioquímicos afetando o metabolismo mitocondrial. Na biópsia muscular encontram-se fibras com arquitetura alterada devido a acúmulo periférico de material granular, o qual é vermelho 


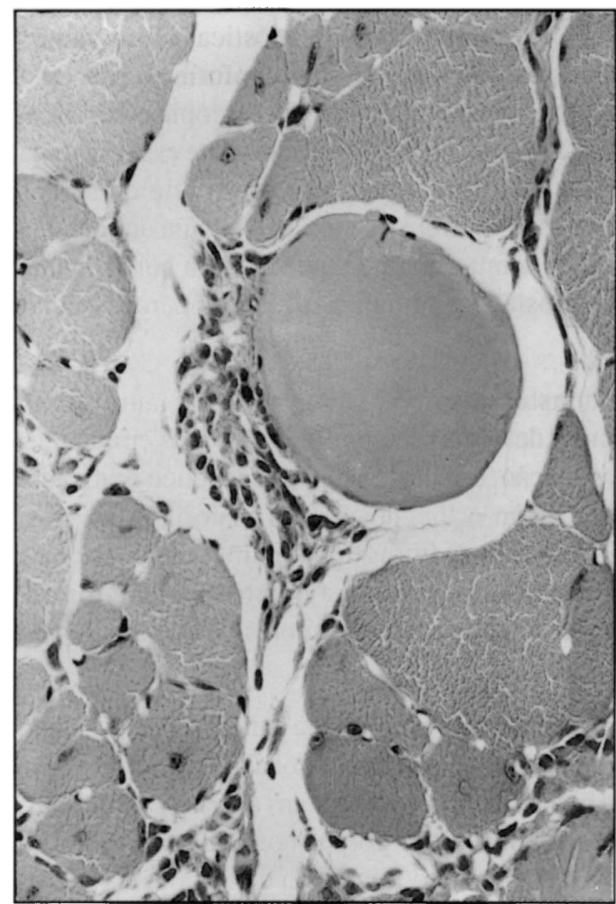

Fig 3. Distrofia muscular demonstrando fibra hipercontrátil e hialina em necrose inicial $(N)$ circundada por fibras que sofreram fagocitose (seta) $e$ outras com núcleos internalizados. Há grande variação no diâmetro das fibras. HE. x100.

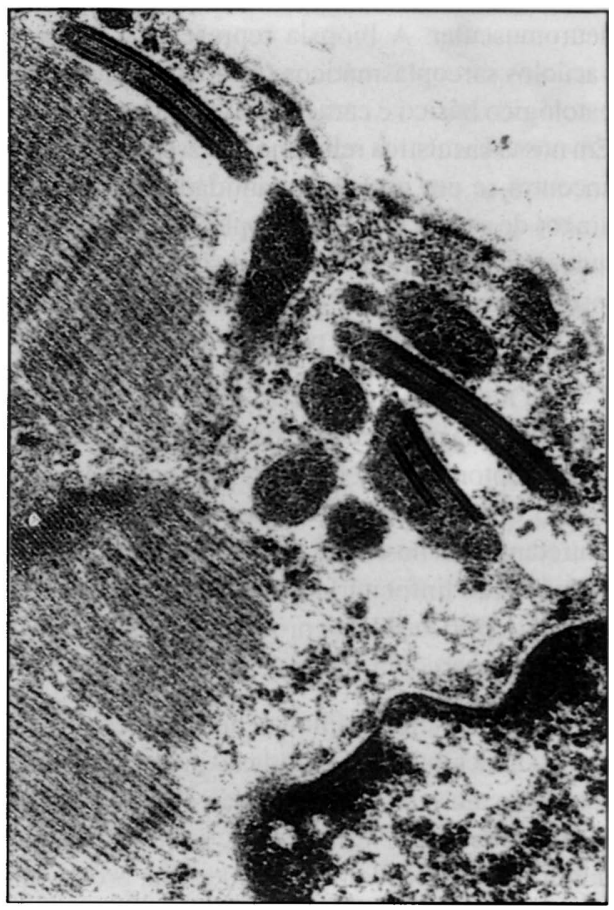

Fig 4. Microscopia eletrônica de fibra muscular de paciente com miopatia mitocondrial demonstrando mitocondrias alongadas contendo inclusões paracristalinas anormais. $x 30000$.

ao tricrômico de Gomori modificado e positivo para enzimas oxidativas tipo succinil desidrogenase e tetrazólio redutase. $\mathrm{Na}$ microscopia eletrônica há aumento do número de mitocôndrias com alteração em forma e tamanho, anormalidades no padrão das cristas e presença de inclusões para-cristalinas (Fig 4).

Contamos ainda com 3 casos de miopatias inflamatórias (dermatopolimiosites), grupo de etiologia obscura, ocasionado por provável mecanismo imunológico relacionado a hipersensibilidade tardia mediada por células. A análise da biópsia muscular demonstra presença de grande número de fibras em necrose com fragmentação citoplasmática ou aspecto vítreo. A regeneração muscular é proeminente com fibras de aspecto basofílico e núcleos vesiculosos. Observam-se, ainda, focos de infiltrado linfocitário perivascular e intersticial com ocasionais plasmócitos. A hipertrofia de fibras musculares é rara em contraste com as distrofias, porém frequentemente nota-se atrofia de fibras com distribuição perifascicular atingindo diâmetros de até 10 micrômetros. Nossa baixa incidência de polimiosite $(2,4 \%)$ diagnosticada em biópsias aproxima-se das observações de Werneck ${ }^{19}$. Se comparada aos $23 \%$ dos casos diagnosticados por $\mathrm{Lee}^{12}$, a diferença pode ser explicada pelo fato de que em nosso meio as miopatias inflamatórias são diagnosticadas pela clínica, testes laboratoriais, eletrofisiológicos e terapêuticos com imunossupressores, sendo infrequente a necessidade de biópsia muscular.

As miopatias metabólicas correspondem a defeitos bioquímicos próprios da fibra muscular, com acúmulo de substâncias em quantidades anormais que impedem o funcionamento adequado do tecido muscular, ou a anormalidades endócrinas ou metabólicas sistêmicas determinantes de doença 
neuromuscular. A biópsia representa a única maneira de confirmação diagnóstica. Observamos vacúolos sarcoplasmáticos (miopatia vacuolar) contendo substâncias variadas conforme o processo patológico básico e caracterizáveis por estudos histoquímicos enzimáticos e microscopia eletrônica. Em nossa casuística relatamos 2 casos de deficiência de carnitina (1,5\%). Normalmente essa proteína encontra-se em grandes quantidades na fibra muscular e é responsável pelo transporte de ácidos graxos de cadeia longa do citoplasma para a mitocôndria, onde sofrem beta-oxidação. Sua deficiência induz a quadro de fraqueza muscular por vezes afetando a musculatura cadíaca, com consequente insuficiência cardíaca. A administração exógena desta substância minimiza o quadro neuromuscular nas formas miopáticas puras ${ }^{4,10,13}$.

Outros diagnósticos observados incluem miastenia gravis $(n=1)$, doença autoimune caracterizada por alteração da transmissão neuromuscular devida à presença de anticorpos circulantes anti receptores de acetilcolina pós-sinápticos. Nesta situação, a biópsia muscular é pouco realizada, pois o quadro clínico e as provas terapêuticas estabelecem o diagnóstico na maioria dos casos. Entretanto, em nosso caso e nos relatos de literatura ${ }^{3.5}$ há atrofia de fibras tipo II com focos ocasionais de infiltrado linfocitário e alterações no padrão da junção neuromuscular à microscopia eletrônica, como simplificação das pregas pós-sinápticas e redução do número de receptores de acetilcolina na membrana sarcoplasmática.

Observamos, também, aproximadamente $26 \%$ de casos inconclusivos, a maioria deles sendo devida a escolha inapropriada do grupo muscular a ser biopsiado, ou a fase clínica inicial do processo sem lesão muscular estabelecida e em que a análise da biópsia demonstrou apenas alterações mínimas, incaracterísticas. Nestes casos, se nova biópsia fosse realizada em grupo muscular adequado ou durante a fase estabelecida da doença, provavelmente o diagnóstico final seria determinado. Outras causas de laudos inconclusivos foram artefatos de compressão e material insuficiente ou não representativo de tecido muscular. Estes são casos geralmente provenientes de serviços sem a devida orientação para a colheita dessas amostras.

Nota-se ainda que em 9 casos $(7,3 \%)$ só nos foi possível considerar o diagnóstico de doença muscular em estadio terminal, o qual é proveniente da análise de uma biópsia muscular contendo alterações extremamente avançadas como intensa fibrose e infiltração adiposa, alterações comuns a várias neuromiopatias em fase final de evolução. Torna-se, assim, impraticável a elucidação do processo que lhe deu origem.

\section{CONCLUSÃO}

A injúria muscular pode ter origem em doenças que afetam o neurônio motor (doenças neurogênicas), naquelas que alteram a transmissão neuromuscular e em doenças que agridem primariamente a fibra muscular (miopatias). Entretanto frequentemente as apresentações clínicas são comuns a várias desordens neuromusculares e, devido a este fato, a biópsia muscular é o exame que define o diagnóstico ${ }^{15}$. Na presente casuística a biópsia muscular permitiu o diagnóstico etiológico em 75\% dos casos. Para tanto, as técnicas utilizadas devem sempre incluir análise do material congelado em nitrogênio líquido para a pesquisa de padrão enzimático muscular, complementado por avaliação morfométrica e microscopia eletrônica que oferece importantes subsídios anátomopatológicos. Os critérios histológicos utilizados para a separação entre doenças neurogênicas e miopáticas são bem estabelecidos, como demonstrado neste estudo e em outros ${ }^{3,5,6.16,19}$, de maneira que a necrose, regeneração e hipertrofia de fibras musculares são indicadores de miopatia. Entretanto é importante lembrar que nas fases avançadas de atrofias neurogênicas podemos identificar fibras aumentadas de volume, o que significa hipertrofia compensatória, bem como infiltração adiposa e mesmo focos de necrose. Estas alterações, conhecidas como pseudo-miopáticas, podem trazer grande dificuldade diagnóstica, pois induzem a diagnósticos de miopatias primárias ao invés de lesões de origem neurogênica. 
Tanto o uso de um método adequado de coleta como a escolha correta do grupamento muscular a ser biopsiado são importantes para o sucesso deste recurso diagnóstico. Nossas biópsias foram, em sua maioria, realizadas a céu aberto por serviços devidamente orientados quanto às técnicas de manejo deste material. $O$ grupamento muscular a ser biopsiado deve ser sempre aquele envolvido clinicamente pela doença, excluindo-se os severamente afetados, onde somente alterações compatíveis a doença muscular em estadio terminal são esperadas ${ }^{14}$.

Agradecimentos - Os autores agradecem as Biólogas Fádua de Queiroz e Danielle Fuhrman pelas preparações histoquímicas e de microscopia eletrônica, ao Centro de Microscopia Eletrônica da UFPR pela utilização do microscópio Philips EM-300, e a todos os colegas médicos que encaminharam material para análise na UPNM. Projeto registrado no BANPESQ/UFPR - 93003189 e com apoio financeiro do CNPq número 404277/90-0.

\section{REFERÊNCIAS}

1. Arruda WO, Torres LFB, Lombe A, Di Mauro S, Cardoso BS, Teive HAG, De Paolo D, Seixas RR. Mitochondrial myopathy and myocronic epilepsy. Arq Neuropsiquiatr 1990, 48: 32-43.

2. Bancroft JD, Stevens A. Theory and practice of histological techniques. London: Churchill Livingstone, 1982.

3. DeGirolami U, Smith TW. Pathology of skeletal muscle diseases. Am J Pathol 1982, 107: 235-276.

4. DiMauro S. Mitochondrial encephalomyopathies. Brain Pathol 1992, 2: 111-112.

5. Dubowitz V. Muscle Biopsy: a practical approach. London: Bailliere Tindall, 1985.

6. Harriman DGF. Greenfield's neuropathology. London: Edward Arnold, 1992, p 1411-1500.

7. Heffner RR. Muscle pathology. London: Churchill Livingstone, 1984.

8. Heffner RR. Histology for pathologists. New York: Raven Press, 1991, p 81.

9. Ibraghimov-Beskrovnaya $O$ et al. Primary structure of dystrophin-associated glycoproteins linking dystrophin to the extracellular matrix. Nature 1992, 355: 696-702.

10. Johnson MA. Histochemistry in pathology. London: Churchill Livingstone, 1990, p 129.

11. Kaido M et al. Muscle histology in Becker muscular distrophy. Muscle \& Nerve 1991, 14: 1067-1073.

12. Lee YS. The role of muscle biopsy in the diagnosis of neuromuscular disorders. Ann Acad Med Singapore 1989, 8: 410-415.

13. Mastaglia FL, Walton J. Skeletal muscle pathology. London: Churchill Livingstone, 1982.

14. Mubarak SJ et al. Percutaneous muscle biopsy in the diagnosis of neuromuscular disease. J Ped Orthop 1992, 12: 191-196.

15. Schidlich HJ. Diagnostic value of muscle biopsy in neuromuscular diseases. Z Hauthr 1990, 65: 185-186.

16. Swash M. The muscle biopsy in clinical practice. Neurologija 1989, 38: 311-319.

17. Torres LFB, Duchen LW. The mutant $m d x$ : inherited myopathy in the mouse. Morphological studies of nerves, muscles and end-plates. Brain 1987, 110: 269-299.

18. Torres LFB. Inherited neuromuscular diseases in the mouse: a review of the literature. Arq Neuropsiquiatr 1988, 46: 298-307.

19. Werneck LC. O valor da biópsia muscular em neurologia: análise de 290 exames a fresco e pela histoquímica. Rev Bras Clin Terap 1981, 10: 224. 